\title{
Treatment of radiculomyelopathy in two patients with placenta-derived decidua stromal cells
}

\author{
Behnam Sadeghi $^{1} \mathbb{D} \cdot$ Bo Ersmark $^{2} \cdot$ Gianluca Moretti $^{1} \cdot$ Jonas Mattsson $^{3,4} \cdot$ Olle Ringdén $^{1}$
}

Received: 6 August 2019 / Revised: 10 December 2019 / Accepted: 12 December 2019 / Published online: 18 December 2019

(c) Japanese Society of Hematology 2019

\begin{abstract}
Mesenchymal stromal cells may reverse acute inflammatory disorders. The placenta is important in feto-maternal tolerance. We have used placenta-derived decidua stromal cells (DSCs) to treat graft-versus-host disease and found an immunomodulatory and anti-inflammatory effect. We here report the use of DSCs in two patients with radiculomyelopathy. The first patient was a 73-year old man treated with parotidectomy and irradiation for lymphoma of the neck. Following a Yersinia infection, he developed a radiculomyelopathy in $\mathrm{C} 3 / \mathrm{C} 4$ and could not elevate his arms. The second patient was a 34-year old woman who was admitted 8 months after allogeneic hematopoietic stem cell transplantation due to hemolysis, impaired sensorium below arcus, and difficulty in ambulation. Following intravenous infusion of DSCs $\left(1 \times 10^{6} / \mathrm{kg} / \mathrm{infusion}\right)$, the first patient could elevate his arms to the facial level. He experienced recurrent paralysis after 6 months, and the efficacy of four additional DSC infusions, at subsequent occasions, were limited and transient. The second patient was treated with two doses of DSCs $\left(1 \times 10^{6} / \mathrm{kg} /\right.$ infusion $)$. After cell infusion, she was able to stand on one leg, sensation in the belly normalized, and she was discharged. These two cases suggest that DSCs may be useful in the treatment of neuroinflammatory disorders.
\end{abstract}

Keywords Myelopathy $\cdot$ Decidua stromal cells $\cdot$ Mesenchymal stromal cells $\cdot$ Graft-versus-host disease

\section{Introduction}

Mesenchymal stromal cells (MSCs) have strong immunomodulatory effects and have been widely used [1-4]. We were first to use MSCs for acute graft-versus-host disease (GVHD) [2, 4]. MSCs were used for GVHD, inflammatory disorders, encephalopathies, acute respiratory distress syndrome (ARDS), arthritis and hemorrhage cystitis [1-7]. We

Behnam Sadeghi

behnam.sadeghi@ki.se

1 Translational Cell Therapy Research (TCR), Department of Clinical Science, Intervention and Technology, Karolinska Institutet, KFC, NOVUM, Plan 6, Karolinska University Hospital Huddinge, Hälsovägen 7, 14157 Huddinge, Sweden

2 Department of Neurology, Queen Sofias Hospital, Stockholm, Sweden

3 Department of Oncology and Pathology, Karolinska Institutet, Karolinska University Hospital Huddinge, Stockholm, Sweden

4 Department of Clinical Immunology, Karolinska University Hospital Huddinge, Stockholm, Sweden have used placenta-derived decidua stromal cells (DSCs) for acute and chronic GVHD, ARDS and hemorrhagic cystitis [8-11].

The decidua plays an important role in feto-maternal tolerance [12]. DSCs have stronger immunomodulatory effect than BM-MSCs and are easier to obtain than BM-MSCs $[9,13]$. Here we report two patients, treated with DSCs for radiculomyelopathy.

\section{Case reports}

Patient 1 was a 73-years old German man who in October 2008, due to extranodal, stage 1A, B cell lymphoma, on the left side of neck, was given 30 Gy irradiation in 2 Gy fractions. Following Yersinia enterocolitis in August 2011, he got paresis in the shoulders and arms.

In October 2011, laboratory tests showed IgG positivity and IgA anti-Yersinia antibodies. Spinal fluid and serum showed monoclonal IgG gamma chain antibodies against yersinia. It is not known from the patient's charts if Yersinia growth was found in stool. Peripheral electroneurography was normal. Diagnosis was transverse myelitis. IVIG and 
corticosteroids had no effect. Plasma exchange was not performed. MRI showed atrophy in $\mathrm{C} 3 / \mathrm{C} 4$. He could not raise his arms. Electrophysiological investigations showed severe neuropathy of the lower motor neurons from the spinal cord segment $\mathrm{C} 3 / \mathrm{C} 4$ to $\mathrm{C} 8 / \mathrm{Th} 1$. He had little sensitivity in both arms. Reflexes for biceps, triceps, and brachioradialis were negative in both arms. Reflexes and sensitivity were normal in the lower extremities. The diagnosis was atypical transverse myelitis. Differential diagnosis including multiple sclerosis, Myelin oligodendrocyte glycoprotein (MOG) antibody-related disease, collagen diseases, antiphospholytic syndrome, vasculitis, sarcoidosis, paraneoplastic neurological syndrome could not be excluded. However, clinical manifestations and the physicians' judgment suggested atypical transverse myelitis.

In December 2013, patient 1 was given cyclosporine, $6.25 \mathrm{mg} / \mathrm{kg}$ twice daily for 2 weeks; to prevent immunization against DSCs. Cyclosporine had no effect on the paresis. DSCs were manufactured as previously described in detail [9, 11]. With ethical permissions (2009/4-18-13/4, 2010/452-31/4, 2015/260-31/2). He was given two doses, $1 \times 10^{6} \mathrm{DSCs} / \mathrm{kg}$ i.v. 1 week apart. On the day after, he could lift his arms to the level of his face for the first time in almost a year. After the second dose, he went home and improvement continued. Afterwards, he could go shoping with his wife and carry the bags. Electrophysiological investigation following DSCs infusion showed some improvement with more frequent motor unit activity, especially in the right arm.

Following a $\alpha$-streptococcal infection in January 2014, he had recurrence of paresis in the arms. We speculate that the occurrence of transverse myelitis was due to infectioninduced inflammation in the site at $\mathrm{C} 3 / \mathrm{C} 4$. He got treatment with two doses of DSCs in May. After the first dose, he could elevate his left arm to arcus and his right arm up to the face. His strength was about $60 \%$ normal. He could open doors and hold a glass without assistance. One and 2 weeks later, he was given additional infusions of DSCs, but with no further improvement. From then on, there was an unchanged routine neurophysiological status. MRI shows decreased volume at levels $\mathrm{C} 3$ and $\mathrm{C} 4$. The neurophysiological examination showed loss of motor units, most pronounced on the left side and there were signs of re-innervation in the remaining motor units. The patient had no strength and could not carry bags. Four months later, he could only raise his hands towards the waist.

In September 2014, he received an additional dose of DSCs. After this, he has shown improvement and could lift his arms up to the waist. MRI was unchanged. Following further infusions of DSCs on three occasions he had transient improvements, but the effect was not long lasting.

Patient 2 was a 34-year old woman who underwent allogeneic hematopoietic stem cell transplantation (HSCT) from an unrelated donor in July 2013 due to acute myeloid leukemia (AML) 15, 16.

Eight months after HSCT, the patient had fever and a DAT-positive hemolysis with hemoglobin of $74 \mathrm{~g} / \mathrm{L}$, lactate dehydrogenase (LD) of $4.2 \mu \mathrm{Kat} / 1$ (normal value $<4.3$ for the age $>71$ ) and $0.1 \%$ schistocytes in the blood streak. This may exclude Thrombotic Microangiopathy(TMA). She had mild chronic GVHD with sicca. She had a subacute onset of ascending paresthesia starting in the feet and progressing proximally to the navel, including the perineum area. She developed an unsteady gate, weakness of the legs and reduced sensation in the anal canal. She had decreased sensibility for touch below the navel, all the way caudally to feet. The tendon reflexes were normal in the arms, but brisk in the legs (left patellar and achilles 4+, right patellar and achilles $3+$ ). The muscle strength was normal in the arms, but slightly reduced in the legs (proximally and distally $4+$ ). The toes were flexor on Babinski's test. She could walk straight in the tandem gait test. Romberg's test was pathological. She needed a walker to walk $>5 \mathrm{~m}$. The cranial nerve examination was unrevealing.

MRI of the brain and entire spinal cord were normal and showed no gadolinium contrast enhancement in the spinal cord or the brain. The lumbar puncture showed only 2 mononuclear cells/ $\mu$ l cerebrospinal fluid (CSF), normal albumin and IgG levels and no oligoclonal bands. Serum and CSF did not show evidence of Epstein-Barr virus, parvovirus, varicella zoster virus, HHV6, cytomegalovirus, herpes simplex 1 and 2, Borrelia, enterovirus, JC virus, HTLV or Mycoplasma infection. CSF had no leukemic cells.

Six days after onset of neurological symptoms, peripheral nerve electroneurography $(\mathrm{ENeG})$ was normal, but increased latency of motor evoked potentials in the lower legs upon cortical transcranial magnetic stimulation (TMS), with normal response evoked in hand muscles. Lumbosacral root TMS stimulation elicited normal motor evoked potentials in the lower legs. Somatosensory evoked potentials (SEP) showed a clear increased latency of cortical sensory potentials upon stimulation of the tibial nerves, but normal responses upon stimulation of the median nerves. The results of the SEP indicated a functional disorder of the spinal cord below C6.

She got prednisolone $(15 \mathrm{mg} /$ day $)$ and a dose of intravenous immunoglobulin (IVIG, $30 \mathrm{~g}$ ) for the hemolysis. The neurological symptoms persisted on March 26, i.e. 8 days after onset.

She got DSCs $\left(1 \times 10^{6}\right.$ cells $\left./ \mathrm{kg}\right)$ with no complications 8 days after neurological symptoms. The day after the DSC infusion, she had normal sensation on neurological examination and subjectively in the lower abdomen and legs. She could walk more steadily, had a normal Romberg test and could keep balance standing on one leg. She was discharged and a week later got the second DSC infusion $\left(1.2 \times 10^{6}\right.$ 
cells $/ \mathrm{kg}$ ). The patient had some residual paresthesia in the toes and subjective balance impairment but made long walks without aid. The TMS showed a slight improvement in the latencies of motor evoked potentials in the legs upon cortical stimulation compared to the previous exam. Four months after DSCs therapy walking and sensation were normal. She resumed working 3 months after treatment with DSC. The patient was examined with TMS and SEPs every 3-5 months up to a year after the onset of neurological symptoms. SEPs were completely normal. TMS, although significantly improved, showed some residual delay in the latency of motor evoked potentials to the legs.

Due to hemolysis, the patient continued with steroids, which were tapered after 9 months. One year after infusion, prednisolone was discontinued and she has no more hemolysis. At the last follow-up, the patient is doing well with no neurological symptoms.

\section{Discussion}

In patient 1 we speculated that the symptoms may be due to a previous irradiation and infection-induced inflammation. The investigation showed a clear pathological electromyelography pointing to radiculomyelopathy. The subjective symptomatology in patient 2 indicated a thoracic myelitis. The objective pathological findings in the investigation were clear and confined to evoked potentials.

Both patients had a very dramatic response 1 day after DSC infusion. Patient 1 could elevate his arms. Patient 2 could suddenly walk steadily. In patient 1 the myelopathy re-occurred after 6 months, and the effects of DSC were only transient. In patient 2 , the effects were long-lasting. Some differences between the two patients may explain the differences in outcome. Most importantly, patient 1 had myelopathy for a year, whereas patient 2 had myelopathy for 1 week. This is also experienced with GVHD, where DSC's effectively reverse acute GVHD [11], whereas in chronic GVHD only limited and transient effects were seen [8].

Although DSCs appear to have a potent anti-inflammatory effect, it was not known whether the cells would be effective for myelopathy [9-11, 14].

The anti-inflammatory and immunomodulatory mechanisms by DSCs in not fully understood. However, in vitro in mixed lymphocyte cultures direct contact with DSCs and immune cells are needed for immunosuppression and an increase of regulatory T cells [15]. Interferon gamma, prostaglandin E2, indoleamine dioxygenase and programmed death ligand-1 are probably involved in the mechanism because blocking of these structures using antibodies abrogated immunosuppression by DSCs [15]. Infusion of allogeneic cells may cause immunization. A boy who was treated with DSCs for epidermolysis bullosa developed multispecific anti-HLA antibodies [16]. Anti-HLA antibodies have not found in HSCT patients treated with DSCs [16]. Studies in mice have also shown that stromal cells induce immunization [16]. To prevent immunization, the first patient was given CyA.

Patient 2 developed a subacute myelopathy at the thoracic spinal level. At this time, she also had a DAT-positive hemolytic anemia and chronic GVHD with sicca reaction. The neurological examination and results of the electrophysiological testing with TMS and SEP indicated a clear functional disorder of the spinal cord despite normal results of imaging and CSF analysis. This was presumed to have an autoimmune (chronic GVHD) basis. This is most probably the reason although paraneoplastic syndrome or TMA cannot be definitely excluded.

The occurrence of GVHD in the CNS is debated, but the affection of the brain, and also the spinal cord (myelopathy), has been described $[17,18]$. Causes other than GVHDinduced myelopathy (myelitis) were excluded by a thorough workup of possible viral and infectious factors in blood and CSF, and also by ruling outside effects of drugs.

Based on the outcome in these two patients with paresis, further studies using DSCs are warranted. DSCs may also be investigated as a therapy in autoimmune and inflammatory neurological disorders such as Myasthenia Gravis and Guillain-Barré disease.

Acknowledgements We thank Gunilla Tillinger for preparation of this manuscript. This work was supported by grants to OR from the Swedish Cancer Society (CAN2013/671), the Swedish Research Council (K2014-64X-05971-34-4), the Cancer Society in Stockholm (111293). OR was the recipient of a Distinguished Professor Award from the Karolinska Institutet.

\section{Compilance with ethical standards}

Conflict of interest The author declares that they have no conflict of interest to report.

\section{References}

1. Augello A, Tasso R, Negrini SM, Cancedda R, Pennesi G. Cell therapy using allogeneic bone marrow mesenchymal stem cells prevents tissue damage in collagen-induced arthritis. Arthritis Rheum. 2007;56(4):1175-86.

2. Le Blanc K, Rasmusson I, Sundberg B, Gotherstrom C, Hassan M, Uzunel M, et al. Treatment of severe acute graft-versus-host disease with third party haploidentical mesenchymal stem cells. Lancet. 2004;363(9419):1439-41.

3. Martinez-Montiel Mdel P, Gomez-Gomez GJ, Flores AI. Therapy with stem cells in inflammatory bowel disease. World J Gastroenterol. 2014;20(5):1211-27.

4. Ringden O, Uzunel M, Rasmusson I, Remberger M, Sundberg B, Lonnies H, et al. Mesenchymal stem cells for treatment of therapy-resistant graft-versus-host disease. Transplantation. 2006;81(10):1390-7. 
5. Ringden O, Uzunel M, Sundberg B, Lonnies L, Nava S, Gustafsson $\mathrm{J}$, et al. Tissue repair using allogeneic mesenchymal stem cells for hemorrhagic cystitis, pneumomediastinum and perforated colon. Leukemia. 2007;21(11):2271-6.

6. Zappia E, Casazza S, Pedemonte E, Benvenuto F, Bonanni I, Gerdoni E, et al. Mesenchymal stem cells ameliorate experimental autoimmune encephalomyelitis inducing T-cell anergy. Blood. 2005;106(5):1755-61.

7. Zheng G, Huang L, Tong H, Shu Q, Hu Y, Ge M, et al. Treatment of acute respiratory distress syndrome with allogeneic adiposederived mesenchymal stem cells: a randomized, placebo-controlled pilot study. Respir Res. 2014;4(15):39.

8. Erkers T, Kaipe H, Nava S, Mollden P, Gustafsson B, Axelsson R, et al. Treatment of severe chronic graft-versus-host disease with decidual stromal cells and tracing with (111)indium radiolabeling. Stem Cells Dev. 2015;24(2):253-63.

9. Ringden O, Erkers T, Nava S, Uzunel M, Iwarsson E, Conrad $\mathrm{R}$, et al. Fetal membrane cells for treatment of steroid-refractory acute graft-versus-host disease. Stem Cells. 2013;31(3):592-601.

10. Ringden OSM, Erkers T, Nava S, Molldén P, Hultcrantz M, Kaipe $\mathrm{H}$, Mattsson J. Successful reversal of acute lung injury using placenta-derived decidual stromal cells. J Stem Cell Res Therapy. 2014;4(10):1-5.

11. Ringden O, Baygan A, Remberger M, Gustafsson B, Winiarski J, Khoein B, et al. Placenta-derived decidua stromal cells for treatment of severe acute graft-versus-host disease. Stem Cells Transl Med. 2018;7(4):325-31.

12. Trowsdale J, Betz AG. Mother's little helpers: mechanisms of maternal-fetal tolerance. Nat Immunol. 2006;7(3):241-6.
13. Karlsson H, Erkers T, Nava S, Ruhm S, Westgren M, Ringden O. Stromal cells from term fetal membrane are highly suppressive in allogeneic settings in vitro. Clin Exp Immunol. 2012;167(3):543-55.

14. Aronsson-Kurttila W, Baygan A, Moretti G, Remberger M, Khoein B, Moll G, et al. Placenta-derived decidua stromal cells for hemorrhagic cystitis after stem cell transplantation. Acta Haematol. 2018;139(2):106-14.

15. Erkers T, Nava S, Yosef J, Ringden O, Kaipe H. Decidual stromal cells promote regulatory $\mathrm{T}$ cells and suppress alloreactivity in a cell contact-dependent manner. Stem Cells Dev. 2013;22(19):2596-605.

16. Kaipe H, Carlson LM, Erkers T, Nava S, Mollden P, Gustafsson $\mathrm{B}$, et al. Immunogenicity of decidual stromal cells in an epidermolysis bullosa patient and in allogeneic hematopoietic stem cell transplantation patients. Stem Cells Dev. 2015;24(12):1471-82.

17. Sakai M, Ohashi K, Ohta K, Yamashita T, Akiyama H, Kisida S, et al. Immune-mediated myelopathy following allogeneic stem cell transplantation. Int J Hematol. 2006;84(3):272-5.

18. Openshaw H, Slatkin NE, Parker PM, Forman SJ. Immune-mediated myelopathy after allogeneic marrow transplantation. Bone Marrow Transpl. 1995;15(4):633-6.

Publisher's Note Springer Nature remains neutral with regard to jurisdictional claims in published maps and institutional affiliations. 